\title{
PROGRESSOS DA NANOTECNOLOGIA NO TRATAMENTO TUMORAL: UMA REVISÃO SISTEMÁTICA
}

\author{
Amon Vitorino Duarte ${ }^{l}$; Yara Talita Gomes Pereira ${ }^{l}$; Barbara Torquato Alves ${ }^{l}$; \\ Kevellyn Cruz Aguilera ${ }^{l}$; Ana Maria Lima Carneiro de Andrade ${ }^{1}$; \\ Rivania Beatriz Novais Lima ${ }^{1}$; Ricardo Souto Quidute ${ }^{2}$.
}

Introdução: A ciência da nanotecnologia baseia-se na manipulação de átomos, moléculas e estruturas supramoleculares para originar e utilizar materiais em escala manométrica. Esses nanomateriais no contexto oncológico (nanocarreadores) são internalizados pelas células, possibilitando uma liberação prolongada de substância no sitio de ação e, com isso, ampliando a utilidade da droga antineoplasica. Objetivos: mapear as evidencias cientificas relativos ao estudos in vivo, envolvendo nanocarreadores lipídicos contendo fármacos citotóxicos voltados ao tratamento de tumores. Método: revisão sistemática de literatura de estudos primários e secundários, realizado no período de 2010 a 2017, nas seguintes bases de dados: PubMed, Scielo e LILACS. Utilizou-se os descritores: nanotechnology, treatment, além da palavra-chave: câncer, combinados com operador booleano and, conforme a seguinte equação de busca: treatment and nanotechnology and câncer. Resultados: O uso dos descritores resultou em 5795 estudos, que após usar os critérios de inclusão e exclusão (artigos na integra, em inglês e português, testes em ratos e em humanos e artigos que contemplavam o tema) foram selecionados 25 artigos. Os principais resultados desses estudos mostram que hoje há vários nanoparticulas aprovadas pelo Food and Drug Administration (FDA). Em meio a essas, destacam-se: formulações lipossomais de doxorrubicina, a Doxil®, que foram os primeiros nanocarreadores aprovados para carrear uma série de quimioterápicos, trata o câncer de ovário, e está em fase experimental em ratos para o desenvolvimento de nanoparticulas lipídica solidas contendo o quimioterápico para ser usado de forma direcionada no câncer de pele. Outro exemplo é o Abraxane ${ }^{\circledR}$, no qual o quimioterápico paclitaxel associado à albumina, para tratar câncer de mama e pâncreas. Há muitos testes pré-clínicos que revelam um potencial de novos fármacos. Essas novas macromoléculas são peptídeos, plasmídeos e, recentemente, inibidores de genes por silenciamento de RNA de interferência. Conclusão: $\mathrm{O}$ uso de nanocarreadores como forma de entrega de drogas pode potencializar as propriedades farmacológicas dos compostos normalmente utilizados no tratamento de câncer. Muitos desses foram aprovados para uso clínico e outros encontram agora em estágio de testes clínicos. Os oncologistas, no futuro, devem contar com arranjos especiais de nanocarreadores e moléculas alvo, que, seguramente contribuiriam nos resultados terapêuticos.

Palavras chave: Câncer. Nanotecnologia. Tratamento tumoral.

\footnotetext{
${ }^{1}$ Acadêmicos da Faculdade de medicina Estácio de Juazeiro do Norte e membros da Liga acadêmica de oncologia (LAON).

${ }^{2}$ Médico pela Faculdade de Ciências Médicas de Pernambuco. Residência médica em Cirurgia geral pelo hospital Agamenon Magalhães. Residência médica em Mastologia pelo Hospital Universitario Oswaldo Cruz. Aperfeiçoamento em Advanced Course on Mastology- Current Management no instituto Eoropeo di Oncologia,IEO,Itália. Diretor clinico no Instituto de mama. Professor da Estácio - FMJ e orientador da Liga de oncologia (LAON).

Autor correspondente: amonduartemed@gmail.com
}

2 Id on Line Rev. Mult. Psic. V.12, N. 40. 2018 - ISSN 1981-1179 EDIÇÃO ESPECIAL: I CURSO DE ONCOLOGIA DO CARIRI / II JORNADA DE PESQUISA QUANTI-QUALITATIVA EM ONCSOLOGIA. JUAZEIRO DO NORTE, 05 A 10 DE MARÇO DE 2018. Edição eletrônica em http://idonline.emnuvens.com.br/id 